\title{
Erratum to: Clinical efficacy and treatment persistence of monthly minodronate for osteoporotic patients unsatisfied with, and shifted from, daily or weekly bisphosphonates: the BP-MUSASHI study
}

\author{
A. Sakai • S. Ikeda $\cdot$ N. Okimoto $\cdot$ H. Matsumoto $\cdot$ \\ K. Teshima • Y. Okazaki • F. Fukuda $\cdot$ S. Arita • \\ H. Tsurukami • M. Nagashima • T. Yoshioka
}

Published online: 22 August 2014

(C) International Osteoporosis Foundation and National Osteoporosis Foundation 2014

\section{Erratum to: Osteoporos Int}

DOI 10.1007/s00198-014-2756-8

In the second paragraph of the Introduction section, the last portion of the first sentence states: ".. and approved for use for the treatment of osteoporosis in Japan [11]." This was inadequately referenced, and should be "approved for use for the treatment of osteoporosis in Japan [11, 17-19]."

In the fourth paragraph of the Discussion section, the first portion of the first sentence states: "While many

The online version of the original article can be found at http://dx.doi.org/ 10.1007/s00198-014-2756-8.

\section{A. Sakai $(\square)$}

Department of Orthopaedic Surgery, School of Medicine, University

of Occupational and Environmental Health, 1-1 Iseigaoka,

Yahatanishi-ku, Kitakyushu 807-8555, Japan

e-mail: a-sakai@med.uoeh-u.ac.jp

\section{S. Ikeda}

Department of Orthopaedic Surgery, Ken-Ai Memorial Hospital,

Onga, Japan

\section{N. Okimoto}

Okimoto Clinic, Kure, Japan, Okamoto Orthopaedics and Sports

Clinic, Hiroshima, Japan

H. Matsumoto

Department of Orthopaedic Surgery, Sanzai Hospital, Saito, Japan

K. Teshima

Teshima Orthopaedic Clinic, Kitakyushu, Japan

Y. Okazaki

Department of Orthopaedic Surgery, Makiyama Central Hospital, Fukuoka, Japan reports have indicated the bone density-increasing effects of switching to daily minodronate from other BPs [11, 17-19], ..." This was incorrectly referenced, and should be "While many reports have indicated the bone density-increasing effects of switching to daily minodronate from other BPs [23-25], ..."

In the fifth paragraph of the Discussion section, the first portion of the first sentence states: "While daily minodronate has been reported to alleviate low back pain [19], ...". Additionally, in the sixth paragraph of the Discussion section, the first sentence states: "We have already reported that daily

\section{F. Fukuda}

Department of Orthopaedic Surgery, Kitakyushu General Hospital, Kitakyushu, Japan

S. Arita

Department of Orthopaedic Surgery, Obase Hospital, Miyako, Japan

H. Tsurukami

Tsurukami Clinic of Orthopaedic and Rheumatology, Kumamoto, Japan

\section{Nagashima}

Katsuki Neurosurgery and Orthopaedic Clinic, Nogata, Japan

T. Yoshioka

Department of Orthopaedic Surgery, Sakamidorii Hospital,

Hiroshima, Japan 
minodronate treatment induced fewer GI symptoms in comparison with weekly alendronate treatment [19]." The reference number [19] is incorrect and should be [18] in both cases.

An inappropriate publication was cited as reference 21 . The correct reference is:

21. Nozaki K, Kakimoto S, Kimoto A, Yoshino T, Sato Y, Yoshida A, Nakamura T (2011) Investigation into the analgesic effects of minodronic acid hydrate via $\mathrm{P} 2 \mathrm{X}_{2 / 3}$ receptor (in Japanese). Shinyaku To Rinsho (J New Rem Clin) 60(9):1766-1774

The following three publications should have been included in the References section.
23. Shimoda J (2010) Clinical experience with minodronate for the treatment of osteoporosis unresponsive to alendronate therapy (in Japanese). Osteoporosis Jpn 18(4):739-744

24. Kogawa R, Takagi H (2011) Clinical efficacy of minodronic acid hydrate, a newly developed bisphosphonate, in osteoporotic patients who responded poorly to alendronate therapy (in Japanese). Osteoporosis Jpn 19(4):725-734

25. Matsui H (2012) Clinical effects of minodronic acid hydrate in patients with postmenopausal osteoporosis who underwent first bisphosphonate therapy or pretreatment with risedronate (in Japanese). Central Japan Association of Orthopaedic Surgery \& Traumatology 55(3):531-532 